\title{
Employee Engagement and Staff Turnover and Its Implication on the Organisational Performance: Case of AON Botswana
}

\author{
Theophilus Tebetso Tshukudu \\ Department of Management, Faculty of Business, University of Botswana, Gaborone, Botswana
}

Email address:

tshukudutt@ub.ac.bw

\section{To cite this article:}

Theophilus Tebetso Tshukudu. Employee Engagement and Staff Turnover and Its Implication on the Organisational Performance: Case of AON Botswana. International Journal of Economic Behavior and Organization. Vol. 8, No. 1, 2020, pp. 1-11.

doi: $10.11648 /$ j.ijebo.20200801.11

Received: December 12, 2019; Accepted: February 18, 2020; Published: April 1, 2020

\begin{abstract}
Executive Summary: Secondary data is used to study the relationship between employee engagement and staff turnover and their implication on organisational performance. The discussions contained herein show that employee engagement has a positive relationship and significant effect on organisational performance whilst on the other hand staff turnover has a negative and significant effect on organisational performance thereby confirming the robustness of the relationship between engagement and productivity. Employee engagement has attracted much attention from many scholars as a popular organizational concept in the recent years. It is believed that an engaged employee becomes aware of business context, and works with other colleagues to improve performance within the job for the benefit of the organization. Employee engagement is also linked to staff turnover in that when employees are engaged they tend to be happy and would not leave the organisation, so promoting employee engagement would bring a solution to organisations faced with a challenge of staff turnover which will directly be linked to an organization's improved performance. In this paper a literature review from various research findings and corporate practices are employed using a descriptive study technique. It projects the impact of employee engagement on organization's productivity. It also presents the factors influencing the employee engagement, staff turnover and organizational outcomes.
\end{abstract}

Keywords: Employee Engagement, Staff Turnover, Implication on Organisational Performance

\section{Introduction}

The paper is a study of the relationship between employee engagement and staff turnover and its implications to the overall organizational performance. The paper contains the executive summary, which is the abstract of the research; the background information of $\mathrm{AON}$ Botswana (Pty) Ltd herein referred to as AON; the problem statement; the aim of the study and the significance of the study. It also contains literature review, which is segmented into definition of terms, evolution and relationship between employee engagement and staff turnover, implications on organizational performance and literature review conclusion; discussion, findings, recommendations comprising of 5 bullet points on growth, retention, delivering colleague value, service delivery and compliance; summary and conclusion, and appendices. Tables and figures showing the SWOT analysis of AON Botswana, High Level Strategic Targets for AON Botswana, results of the global employee engagement surveys, employee engagement model, Global trends on employee engagement are included throughout the paper to support the discussions made in the study. The last segment is the appendices, which comprises of references.

\section{Background}

AON Botswana is part of a leading global professional services firm AON PLC (NYSE: AON) providing a broad range of risk, retirement and staff solutions. AON Botswana 
has over 180 colleagues in 2 offices across the country to empower results for clients by using proprietary data and analytics to deliver insights that reduce volatility and improve performance. It is the vision of $\mathrm{AON}$ to be a universally recognised preeminent firm focused on risk and people. AON strives to empower economic and human possibility for clients, colleagues and communities. AON has 3 main operating divisions, Aon Hewitt, Aon Risk Solutions (ARS) and Aon Risk Management (ARM) with a central shared services corporate office in Gaborone. AON in 2017 completed its strategic planning process in Palapye, Botswana attended by the senior leadership team across the various divisions. An overview of the strategic direction based on the shareholder's position and Board's perception for 5-year strategic period 2018 through to 2022 has been provided in a form of a corporate strategy, providing turnaround strategic interventions. $\mathrm{AON}$ is a company that is growing and intends to sustain that momentum. Aon however requires a new set of strategies to guide its growth, build a solid financial foundation, protect its existing base, deliver excellent service and be well positioned for challenges that lie ahead.

There are no statistics available showing that staff turnover has been a problem at AON Botswana, but there are a few citable cases that that there has been voluntary exit in December 2018 whereby about 20 employees left the company. In addition, there has been another early retirement package before the voluntary exit in 2018. There have also been employees who have been leaving the organization because of better offers elsewhere. These cases are a sign that staff turnover do exist at AON Botswana and one way or the other have to be address. As a market leader in insurance broking, AON may be hesitant to provide such statistics as it could compromise its position in the market.

The company had to distinguish itself from its competitors as the leading broker and provider of financial solutions, achieving expected results in both the short-term and medium-term. The economic context for the company had changed, characterized by increasing challenges on governance and compliance from the regulator, pressure on growth from slowing global markets, increased sophistication in customer expectations and the impact of millennials who are challenging fast held practices in the industry and demand greater usage of technology and data to satisfy them. AON must build the right capacity in its people to deliver on these expectations and rise to the challenges ahead. Key is to grow and retain talent in the various business areas, transform the culture within Aon to be more proactive rather than reactive and maintain a strong positive mental attitude to be winners.

AON has used its value gap as the starting point for the strategy to define the difference between the company's aspirations and its current performance or baseline. Although the vision statement articulates the aspirations, the value gap translates them into measurable targets. The prioritised value gap indicators or measures include; strategic intentions for 2018 - 2022 on growth, retention, service delivery and compliance; segment profit before tax and investments (SPTI) growth of 3\% annually until 2022; Revenue growth compounded annually by $7 \%$ until 2022; Cost management on SIB Costs, Non-SIB Costs, Revenue and Cost Ratio spread by $3 \%$ [1]. This brings the discussion to the problem that $\mathrm{AON}$ is facing in order to explicitly achieve its set strategic goals demonstrated in Figure 1 below and achieve high performance due to factors such as employee engagement and turnover.

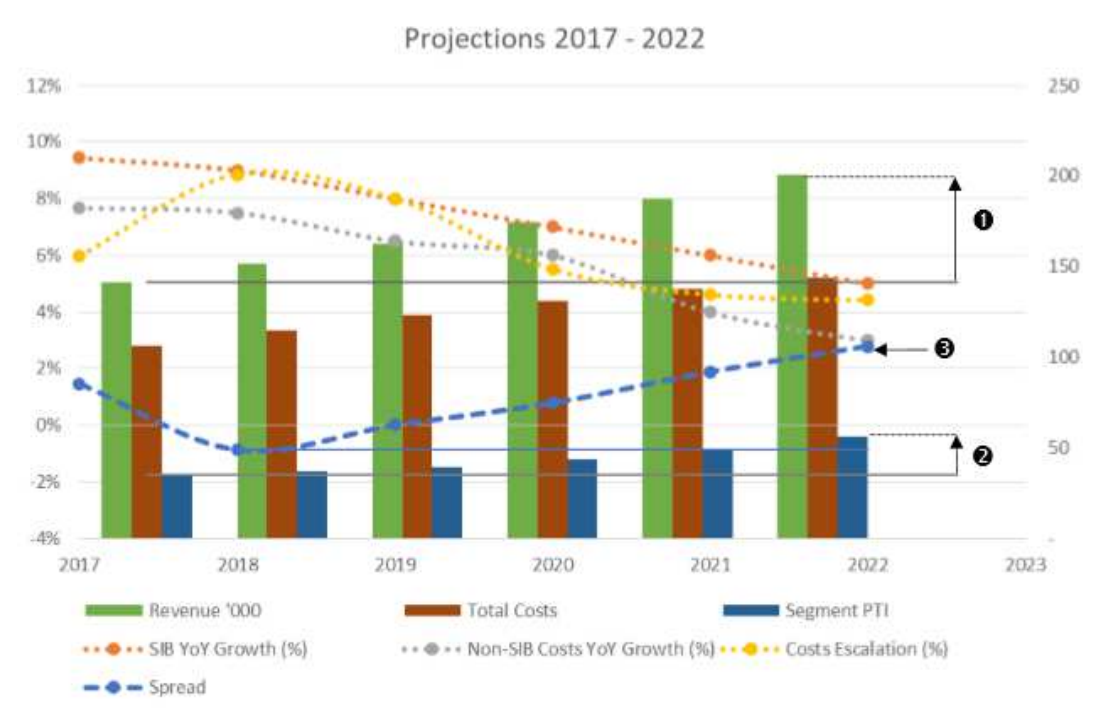

Figure 1. High Level Strategic Targets for AON Botswana, Source [2].

\section{Problem Statement}

Critical leadership challenges, identified as employee engagement and employee turnover, have attracted a lot of interest in both academic and practitioner grounds. Most companies have their corporate or business strategies in place but are still faced with a problem of implementation and 
hence there remain unresolved fundamental issues and gaps. Organisations often fail to connect the strategies on employee engagement and employee retention strategies to their business strategy to be able to achieve their intended organizational performance. The management team in organisations tends to have limited insight on how specific employee engagement and retention strategies impact organizational performance.

\section{Aim of the Study}

1. To study the impact of employee engagement and staff turnover on organizational performance.

2. To explore and recommend strategic priorities and themes to turn around employee engagement and staff turnover to improve overall organizational performance.

\section{Significance of the Study}

The future of Human resources initiatives rests on developing strategic solutions that clearly help leaders to see established links between organizational goals and outcomes. Empowering economic and human possibility for clients, employees and communities around the world is what drives AON. It is a value-based organisation with values such as trust, openness, commitment, teamwork, integrity and innovation. These values are applied in every aspect of what is done at $\mathrm{AON}$, at all levels of the organisation, whether dealing with clients, suppliers, stakeholders and/or employees. Integrity is AON's core value and the guiding principle for how to approach its work, business relationships, decisions and actions. AON lives this value by following the Code of Conduct, doing what they say they are going to do and by always conducting business according to the highest ethical and legal standards. The AON culture values creativity, continuous learning from formal programs, work, clients, and each other and the freedom to try new things. Creativity enables the organisation to solve problems for clients that others cannot. There's only one way to do business, the right way. At $\mathrm{AON}$, the right way means demonstrating the highest levels of integrity in a highly principled, moral, and ethical manner.

The results of the study will help managers do a better job of defining value for strategies recommended and implement them to support, build and sustain an engaged workforce. Other solutions that AON can adopt include engaging in strategic priorities such as talent management, developing great incentives for instance fair bonus structure and adopting other non-monetary incentives, develop a top talent retention model and providing secondments opportunities to employees to be temporarily transferred to other country offices to build new market and product growth. These priorities will encourage employee engagement and help retain employees within the organization hence protect market share through increased retention and cross selling focus. When employees are happy they stick around so the organisations should ensure to introduce strategies and activities that involve the employees so that they would not find need to look for them outside of the organization.

\section{Literature Review}

\subsection{Introduction to Literature Review}

The literature review is segmented into sub topics, which includes the first segment 7.1 being introduction to literature review, definition of terms on segment 7.2, segment 7.3 covers the evolution and the relationship between employee engagement and staff turnover. The majority of the research that touches on the relationship between employee engagement and turnover claims that employee engagement reduces the risk of high employee turnover. The investigations to this link though are rather superficial and there is a lack of evidence [6]. Segment 7.4 talks to drivers of employee engagement and staff turnover, implications on organizational performance on segment 7.5 and lastly segment 7.6 being literature review conclusion.

\subsection{Definition of Terms}

Employee is an individual that received any payroll payment during the pay period that includes the 12th day of the month.

Employee engagement is loosely defined as the level to which employees are fully involved in their work, committed to their work, care about their organization and colleagues and are willing to extend themselves and go the extra mile for their company to ensure its success [7]. Employee engagement in performance terms is employee's willingness and ability to contribute to company success by freely giving the extra effort on an ongoing basis. Thus, it represents the extent to which employees put discretionary effort into their work, in the form of extra time, brainpower, and energy. The combination of "the will" and "the way", the emotional and rational duality leads to full engagement. [8].

Staff turnover is a critical issue in an organization because this leads to increasing financial costs for hiring and training new employees and possibly has a negative impact on sales growth [9]. Disengaged employees uncouple themselves from work roles and withdraw cognitively and emotionally [10].

We may classify Organisational Performance into financial performance and non-financial performance. The financial performance approach examines indicators such as sales growth, profit rate, return on investment, return on sales, return on equity, and earnings per share, whereas the non-financial performance approach focuses on market share, new product introduction, product quality, marketing effectiveness, and technological efficiency [11].

\subsection{Evolution and Relationship Between Employee Engagement and Staff Turnover}

The academic literature on engagement has seen a proliferation of different conceptualisations and 
operationalisations of the construct, which has somewhat impeded its theoretical development [12]. The driving force behind the popularity of employee engagement is that it has positive consequences for organizations [13]. Employee engagement is a good tool to help every organisation to strive to gain competitive advantage over the others [14]. People is one factor that cannot be duplicated or imitated by the competitors and is considered the most valuable asset if managed and engaged properly. It is therefore important to consider the traits of different resources an organization has. Consideration of trait engagement implies a critical link between interventions focused on the early stages of the employment period that is at on-boarding stage and other management-driven activities that relate to the development of state and behavioral engagement at work. Thus, we would further hypothesise that dispositional or trait engagement is a more significant determinant of behavioral and psychological engagement earlier than later in the employment life cycle. Relatedly, engagement may be a consequence of both environmental conditions and dispositional characteristics and their interaction [15].

It is important to first determine the strategic capabilities of an organisation's resources and competences, which is best analysed by SWOT framework in Table 1 below. An effective manager should be able to manage organisation's resources to develop and produce products for the market, achieving the right quality for the right price at the right time [16]. Resources and competencies of the organization underpin its' ability to perform at a level required to survive and. Operationally the measures of engagement have for the most part been composed of a potpourri of items representing one or more of the four different categories: job satisfaction, organizational commitment, psychological empowerment, and job involvement [15].

Table 1. SWOT Analysis for AON Botswana, [2].

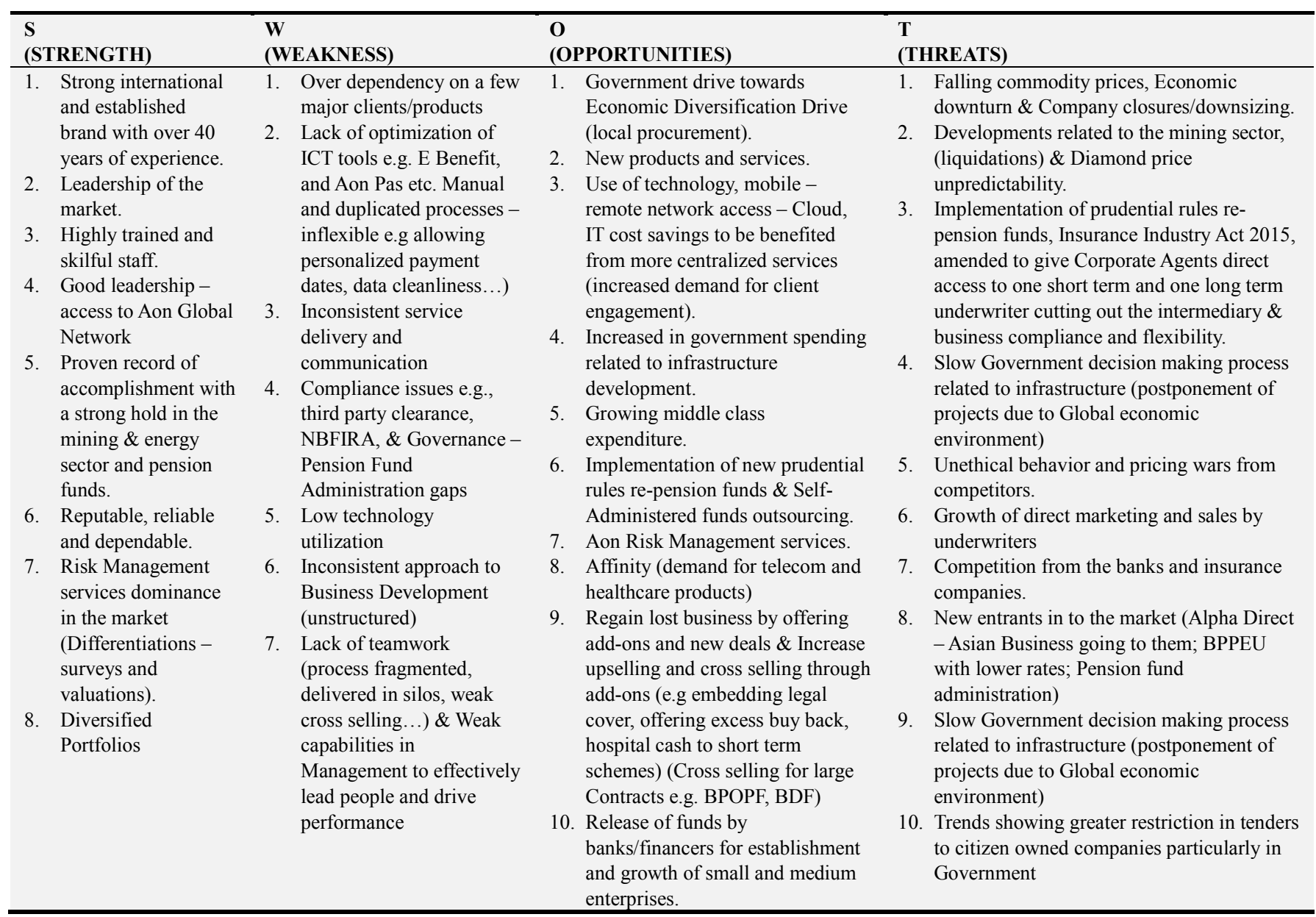

It is evident that the more engaged employees are the more they are likely to stay with an organisation [4]. Many variables can potentially interact to influence both engagement and organisational turnover [17]. They further argued that examining engagement as a mediator for the relationship between organisational factors and turnover has rarely been looked at in the literature. However, given the research evidence demonstrating the impact that climate of diversity, mission fulfilment and interpersonal relationships have on engagement, it is likely that these variables could indirectly influence turnover through their relationship with engagement. AON's employee engagement model shown in the chart below shows drivers of employee engagement, their outcomes and how it translates to business outcomes; 


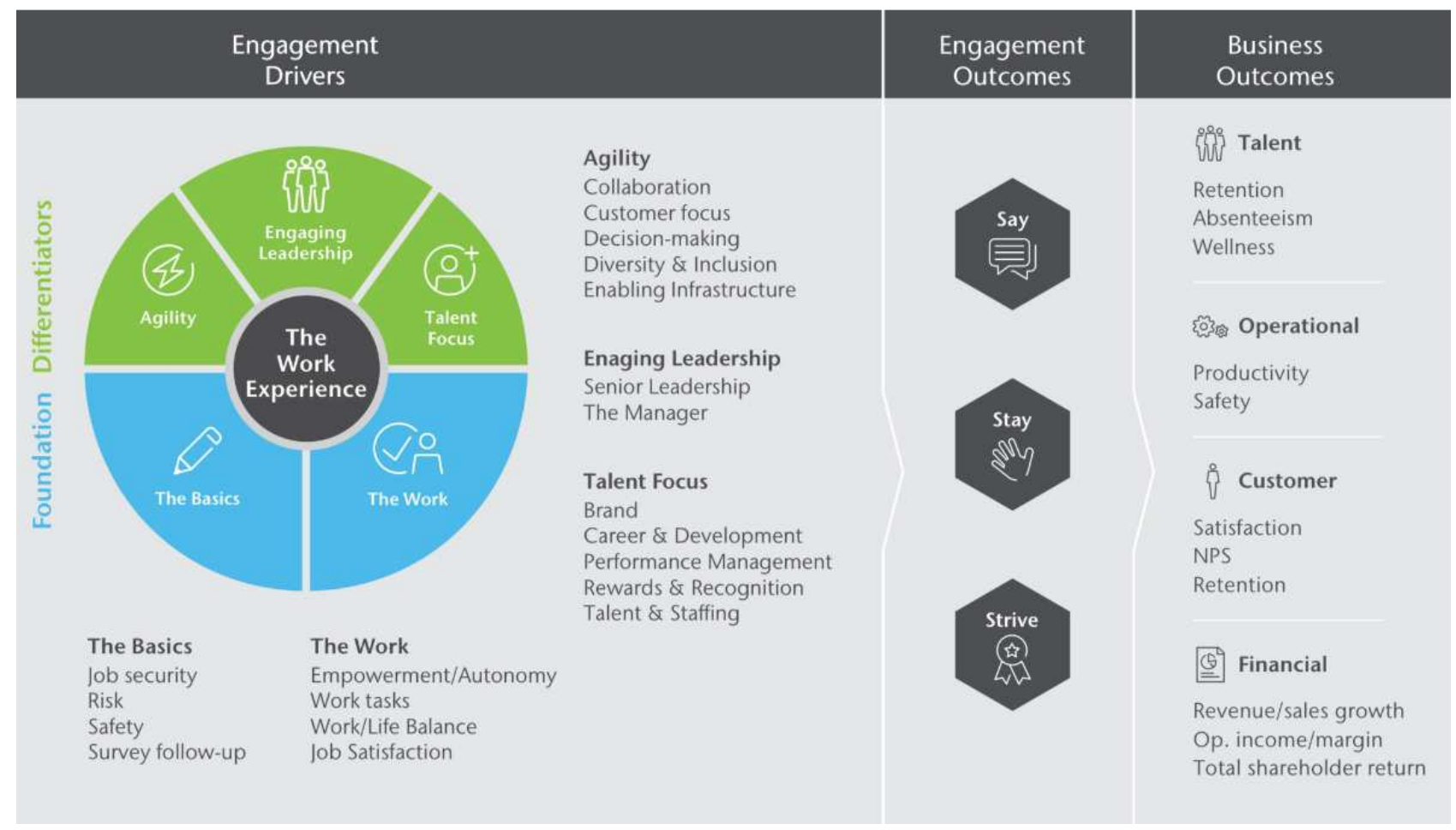

Figure 2. AON Employee Engagement Mode, [18].

A review of the literature suggests work engagement correlates negatively with turnover intention [19],[13]. The AON employee model clearly depicts the engagement outcomes as 'Say', 'Stay' and 'Strive'. This shows that AON is interested in engaging the employees by letting them communicate their ideas, retaining them by letting them stay and also encouraging them to strive to achieve the set business goals. AON's Global Culture \& Engagement Team asserts that people create business value and that is indisputable [18]. This is illustrated by the fact that a software company with 1,000 employees and few physical assets can be worth billions of dollars. People are the intangibles. People are also emotional and fickle. They want to be won over. That is why employee engagement can be an organization's great differentiator in times of stability or in times of rapid change. When you have a culture of engagement, your competitors had better take notice. To discuss how you can create a culture of engagement at your organization, please reach out to one of the contacts on the following page. We are passionate about optimizing the employee experience! (Aon's Global Culture \& Engagement Team) [18]. Engaged employees care about the future of the company and are willing to invest the discretionary effort, exceeding duty's call, to see that the organization succeeds [20].

People's perceptions of meaning about the workplace are clearly linked to their levels of engagement and, ultimately, their performance. Employees actively seek meaning through their work and, unless organisations try to provide a sense of meaning, employees are likely to quit [21]. Engaged employees employ and express themselves physically, cognitively and emotionally during role performances [22].

\subsection{Drivers of Employee Engagement and Staff Turnover}

There are six areas of work-life lead to either burnout or engagement: workload, control, rewards and recognition, community and social support, perceived fairness and values. Job engagement is associated with a sustainable workload, feelings of choice and control, appropriate recognition and reward, a supportive work community, fairness and justice, and meaningful and valued work [23]. Thanks to technology, nowadays business companies are making use of advanced techniques of operation. As sophistication of technologies continues to evolve, they pose more challenges for managers because organizations will have to need more number of employees with increased technical and professional skills. Old styles of totalitarian management cannot manage these knowledge workers. They expect operational autonomy, job satisfaction and status. It is because of these facts that attention of managers is shifting towards employees' side of organizations [24]. Figure 3 below demonstrates the Global trends in employee engagement showing that employee engagement reached its apex in 2015, dropped in 2016 and matched the previous peak in 2017. The high employee engagement is the lower staff turnover would be. 


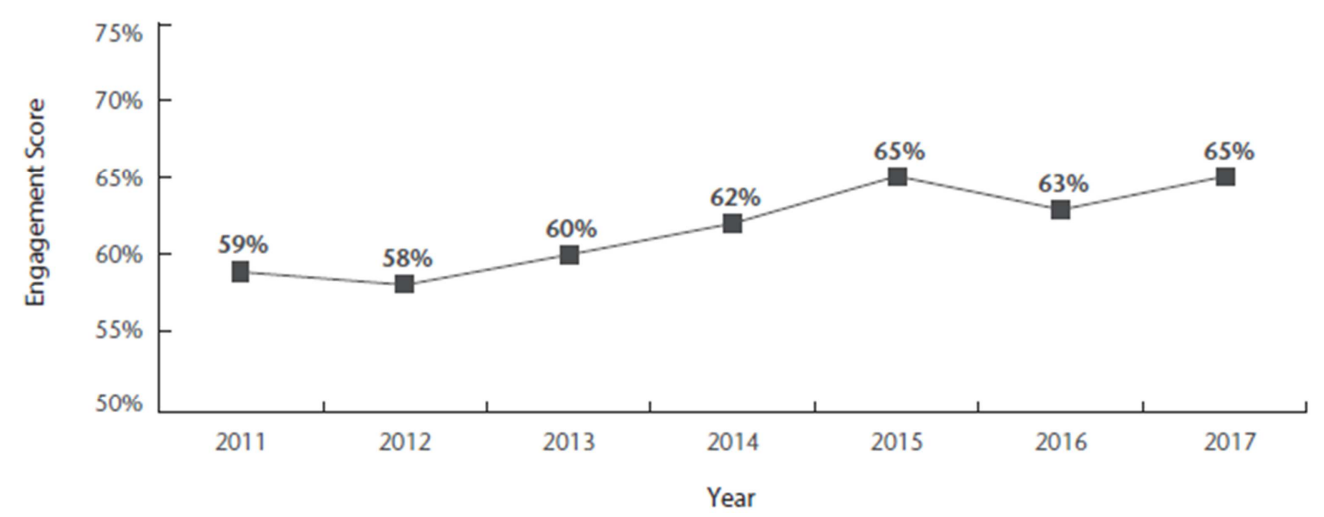

Figure 3. Global Trends in Employee Engagement, [18].

“...pay and benefits are equally important to every employee, good or bad. A company's pay should at least be comparable to the market average. However, bringing pay and benefits package up to market levels, which is a sensible first step, will not take a company very far- they are like tickets to the ballpark, they can get the company into the game, but can't help it win" [24]. One way for individuals to repay their organization is through their level of engagement. In other words, employees will choose to engage themselves to varying degrees and in response to the resources they receive from their organization [13]. Bringing oneself more fully into one's work roles and devoting greater amounts of cognitive, emotional, and physical resources is a very profound way for individuals to respond to an organization's actions.

Globalization, speed, and ambiguity in the business landscape demand the highest levels of fitness to facilitate organizational survival [10]. In such volatile environments, competitors with the correct combination of economic output, trust, innovation and leadership have the greatest prospects of survival. "...researchers have also come up with a new model they called "Hierarchy of engagement" which resembles Maslow's need hierarchy model. In the bottom line there are basic needs of pay and benefits. Once an employee satisfied these needs, then the employee looks to development opportunities, the possibility for promotion and then leadership style will be introduced to the mix in the model." [24]

\subsection{Implication on Organisational Performance}

There exists a direct and indirect relationship among company programs, employee behaviour, customer focus and financial result. Employee engagement and staff turnover are linked, more employee engagement will lead to the low staff turnover. When we look at the implication on organisations performance, we relate it to the relationship between the latter. Many variables affect business outcomes; but there exists a clear relationship between increased engagement, improved retention and better financial performance [8]. Organisational performance differs depending on the type of industry, level of position; long-term versus short-term employment; style of leadership and reasonableness of targets over employee engagement. Drawing on social exchange theory, tested a moderated mediation model linking perceived HRM practices to organisational citizenship behaviour and turnover intentions and posited that human resource management practices are linked with behavioural outcomes. Effect of perceived HRM practices on behavioural outcomes is mediated by levels of employee engagement [25].

The managing director of AON Botswana when communicating the AON corporate strategy for year 2018 through to 2022 in a staff address meeting held in February 2018 mentioned that AON would be concentrating in delivering colleague or employee value. This will be achieved through creating a culture of performance management by embedding the performance management system, developing and implementing an incentive plan that will promote a performance culture (review of share allocation scheme, performance-based pay; review of retention pay \& bonus), tracking the management of performance outcomes to ensure consistency, improve skills capacity and capabilities that drive business performance, implement a robust talent management. (Incorporate secondment to develop high potentials), consistent and comprehensive PMS and development; improve staff retention and reduce attrition of achievers and top talent; develop and implement an effective succession plan aligned to the talent management strategy, implement a top talent development Programme, negotiate and implement preferential staff schemes (loans, loyalty access, discounts), improve leadership and management effectiveness, improve substantive and consistent leadership [26].

\subsection{Literature Review Conclusion}

The literature demonstrates a blurry picture in terms of the relationship between employee engagement and staff turnover. There is not much statistics on staff turnover, more especially for the company discussed herein. Only a few scholars have shown interest in studying staff turnover. Most drivers that lead to employee engagement are non-financial in their nature [24]. 


\section{Discussion}

More and more organisations are realising the value and importance of a happy, engaged company culture. Developing and nurturing employees comes with a lot of benefits to both the employees and the business, in that when the employees are happy because of the way the organization treats them they will commit themselves to performing better hence the organization will achieve business results that when the employees are unhappy. Engaging employees leaves them feeling valued and involved among other employees. It is important that organisations should identify the development needs of their employees. This will the help organisations save on high recruitment costs as staff seek development elsewhere. The organisations that do not implement a satisfactory training scheme are running a risk of increasing their own staff turnover rates because when employees are unhappy they leave the organization. Training is normally considered the most important initiative an organization can engage its employees in. The reasons are probably because when the employees are given practical ways to complete their job more quickly, there will be an increase in productivity. Practical training can also lead to a better quality of work. Obviously, this has a positive knockon effect on customer satisfaction rates too. Upskilling is a growing trend in businesses today due to its significant role in cutting recruitment costs and improving staff retention. The organisations will not have to hire new employees when they offer new services or products to customers but upskilling employees will help the organization save a lot of money and positively expand business growth and increase management opportunities. Instead of trying a new and unknown quantity, you can invest in a reliable employee who might be able to flourish into a role.

AON believes that being a responsible and contributing corporate citizen is necessary to the equitable development of Botswana and is therefore a key component of its business strategy. Over the years AON has invested time and money on various initiatives of giving back to the Community. At AON the core of any organization's citizenship is believed to be how its business contributes to society and in the communities where its employees live and work basically to empower results for clients, colleagues and communities. Citizenship also means going the extra step and contributing to society beyond what you do in your everyday course of business. Through the powerful spirit of volunteerism demonstrated by AON colleagues, the organisation contributes time, expertise and funding to philanthropic organisations that serve communities at risk and empower people, especially the young people in Botswana who are the future of the society. Aon strives every day to live its values, respect ethics and build a diverse and talented team. The company has a strong commitment to service, teamwork, integrity and results, which is how it approaches its interactions with clients, colleagues, communities and the environment. Through AON logo 'Empower Results' the company strives to push past limits towards new possibilities and unseen opportunitiesk hence solving real challenges that affect real people. In and out of the office AON dedicates numerous hours to help communities rebuild, grow and prosper by serving communities at risk in Botswana, empowering human and economic possibility by focusing on programmes or initiatives that encourage gender empowerment and development, promoting health and wellbeing and investing in current and next generation talent.

The programme is a deliberate, focused, coherent and progressive programme that is well coordinated, guided by a common policy framework, has clear focus areas, mutually beneficial to both the employees of $\mathrm{AON}$, the organisation and the country and also seen as a strategic business function, aligned to the core business. The commonly shared objectives of Aon's CSI programme include making a positive, sustainable and measurable impact on the communities in which it operates through investing in improving the quality of life of disadvantaged communities; to develop and empower disadvantaged communities in the social, economic and environmental spheres for the sustainability and long term growth of the Botswana and in turn the company to create and enhance its reputation as a caring corporate citizen; to attract qualified, socially responsible staff to Aon as well as retain and enhance the loyalty and pride of existing staff in the company; to support the strategic positioning of Aon as a contributor to the development of disadvantaged communities.

There are several other initiatives that organisations can adopt to improve their offering like holding monthly meetings with employees to hear their challenges and provide solutions, the organization can also hire a professional to carry out surveys to always receive comments and suggestions of how they can improve the way they lead from the employees. It is no every day that an employee would go to the manager's office to express their gratitude or dissatisfaction but it appears the employees can easily relate to technology, for instance when they complete the surveys they tend to express their real feelings than when it is a faceto-face feedback session.

Organisational culture also have some bearing on productivity or performance of the organization. Culture is the ideas and social behaviours adopted by a group of people. It is therefore extremely important to create a positive culture to ensure the organisation gets the most out of all employees because a toxic organisational culture can severely impact productivity and ultimately lead to a high staff turnover rate. Employee turnover is part and parcel of the business in any industry. Excessive turnover decreases the overall efficiency of a company and is very damaging to the bottom line. In other words, turnover has a cost, and a significant one at that, yet most of the managers still do not seriously consider it as a business damaging effect.

Turnover is where employees leave an organization due to dismissal, attrition, and other reasons. These people will not be on the payroll during the next period. Other reasons of people quitting jobs include lack of contentment resulting from issues such as low salaries. The employees would go 
and look for better paying jobs somewhere else. Overall satisfaction in terms of salaries and benefits are really hard to achieve, because naturally people do not get satisfied easily. Knowing the organisation's turnover rate is very important so that the managers may know what measures they need to put in place to retain their employees. Turnover rate is the percentage at which people leave the company in a given period of time.

Organisations have to go for routine inclusion of turnover metrics in management performance measures. Understanding the effects of a high staff retention rate is a motivator for large to work toward reducing the staff turnover rate and making the company a more appealing place to work. High turnover rates cost the company money and time having to carry out exit interviews, advertising for the job, recruiting candidates, and interviewing for open positions. Staff turnover also turnover hurts group dynamics, particularly in large companies where high employee retention can significantly affect a brand's efficiency for instance. An effective employee retention strategy has two key components which includes identifying employees at risk of leaving and targeting employees at risk with appropriate incentives.

Employee turnover is a large problem for some companies especially when it comes to the company's high potentials. When the organization hires them they really want to keep them but the problem is that they get offered lots of opportunities. When an employee leaves the organization, the organization loses money, knowledge and contacts are lost, it leaves negative impact on colleagues in terms of increased workload, onboarding of new hires takes time, hiring is expensive and involves a lot of costs of recruitment, assessments, onboarding time and training, and also accounting for bad hires.

Staff turnover can be reduced through introducing better rewards like bonuses and allowances, promoting internally will avail development opportunities to employees and will also boost their morale. Job rotation is one way of keeping employees challenged in their job, training managers to be better leaders and employee engagement. Employees who feel engaged employees do not only work harder and become productive, but they generally stay longer as well. It is in light of the above that the discussion can be concluded that both employee engagement and staff turnover have an impact of the overall performance of the organization. Engaged employees will stay longer with the organization whilst disengaged employees are likely to leave. The more the people who leave the organization, the lower the performance of an organization. The more engaged the employees are, the more productive they become.

\section{Findings}

Aon Hewitt's global engagement research from 2008 to 2010 includes 6.7 million employees and represents more than 2,900 organizations. The overall global average employee engagement score is $56 \%$ in 2010 , down from $60 \%$ in 2009. The 4 percentage-point change is due to regional score changes in Asia-Pacific, Europe, and North America. Top 3 engagement drivers are career opportunities, brand alignment, and recognition [2]. This is in line with what most successful organisations do; they understand the value of their employees and as such they try to keep the work as interesting as possible, provide opportunities for growth and advancement, and align skilled workers with the jobs that they are mostly likely to succeed in doing. It is important to note that employees need to believe that they have a chance of advancing through the different ranks as anybody else with the input of time, effort, and creativity. Without feeling that their input will be helpful to either the company or their own careers, employees are unlikely to put forth the extra effort for the company to succeed [27].

Pearson correlation analysis of employee engagement results gave a correlation of 0.533 , which demonstrated that employee engagement has a positive correlation with organization performance. Regression model of employee engagement versus organization performance gave a coefficient of determination of $\mathrm{R}$ square of 0.284 and $\mathrm{R}$ as 0.533 at 0.05 significant level [28]. The coefficient of determination indicated that $28.4 \%$ of the organization performance is explained by employee engagement. This implies that there exists a strong positive relationship between employee engagement and organization performance. [28]. All companies should recognize that their success is dependent on their ability to attract, develop, and retain talented employees and build long-term employee relationships [29]. Managers must be able to foresee and predict future needs for employees and develop specific plans to develop, and retain the type of employees who meet the needs of a high-performing organisation.

Employee engagement for more than 1,000 companies around the globe is measured. Employee engagement is measured every year. This study has been conducted using data from more than 8 million employee responses in 2016 and 2017. The responses come from organizations with as few as 100 employees to the most complex organisations with hundreds of thousands of employees [18]. More than 60 industries are represented in the study. Figure 4 and Figure 5 below shows the findings from the surveys and Africa attained $66 \%$ engagements, whilst globally engagement was $65 \%$. If companies can foresee what would work toward the development and retention of the right types of employees, companies can expect to be successful in a global, dynamic, and continuously-changing competitive environment [29]. Africa's improved employee engagement across many engagement drivers puts the region's organizations in a great position for business growth. Africa's recent economic struggle resulted in leaders placing an increased emphasis on creating growth-driven business environments through more engaged employees by actively listening to them. Driving engagement has become a much larger focus for the regions' companies over the past few years which is clear in the improved results. Now, leadership will need to provide clear direction and strategy for the future in order to position their 
organizations for long-term success (Khalid Youssef, Aon

Employee Engagement Solution Leader) [18].

\section{Key Findings}

\section{Global Engagement Trends}

\begin{tabular}{|c|c|c|c|}
\hline Global & & North America & Latin America \\
\hline $65 \%$ × & pts & $\leftrightarrow$ Opts & $75 \%$ \\
\hline $\begin{array}{l}\text { Top Engagement } \\
\text { Opportunities }\end{array}$ & & $\begin{array}{l}\text { Top Engagement } \\
\text { Opportunities }\end{array}$ & $\begin{array}{l}\text { Top Engagement } \\
\text { Opportunities }\end{array}$ \\
\hline Rewards \& Recognition & $1+3$ & Enabling Infrastructure $\downarrow-1$ & Senior Leaderahip \\
\hline Senior Lesdership & $1+2$ & SeniorLeadership $\quad \leftrightarrow 0$ & Career \& Development $\downarrow-1$ \\
\hline Career \& Development & $f+2$ & Rewards \& Recognition $\uparrow+1$ & Rewards \& Recognition $\leftrightarrow 0$ \\
\hline EVP & $1+3$ & Career \& Development $t+1$ & Takent \& Staffing $\quad 1+2$ \\
\hline Enabling Irfrastructure & $1+2$ & EVP $\quad \leftrightarrow 0$ & Enabing Infrastructure $\leftrightarrow 0$ \\
\hline $\begin{array}{l}\text { Largest Positive } \\
\text { Dimension Increases }\end{array}$ & & $\begin{array}{l}\text { Largest Positive } \\
\text { Dimension Increases }\end{array}$ & $\begin{array}{l}\text { Largest Positive } \\
\text { Dimension Increases }\end{array}$ \\
\hline Talent \& Staffing & $\uparrow+3$ & Mission/Values $\quad t+5$ & Takent \& Staffing $\quad 1+2$ \\
\hline EVP & $\uparrow+3$ & Customer focus $\quad t+3$ & Mssion/Nalues \\
\hline Rewards \& Recognition & $\uparrow+3$ & Diversity \& Inclusion $\quad \uparrow+2$ & Work Tasks \\
\hline Ensbling Infrastructure & $\uparrow+2$ & Rewards \& Recognition $t+1$ & $\uparrow+1$ \\
\hline Career \& Development & $\uparrow+2$ & Talent $\&$ Staffing & \\
\hline
\end{tabular}

Figure 4. Results of Global Survey- Global Engagement Trends 2017, [18].

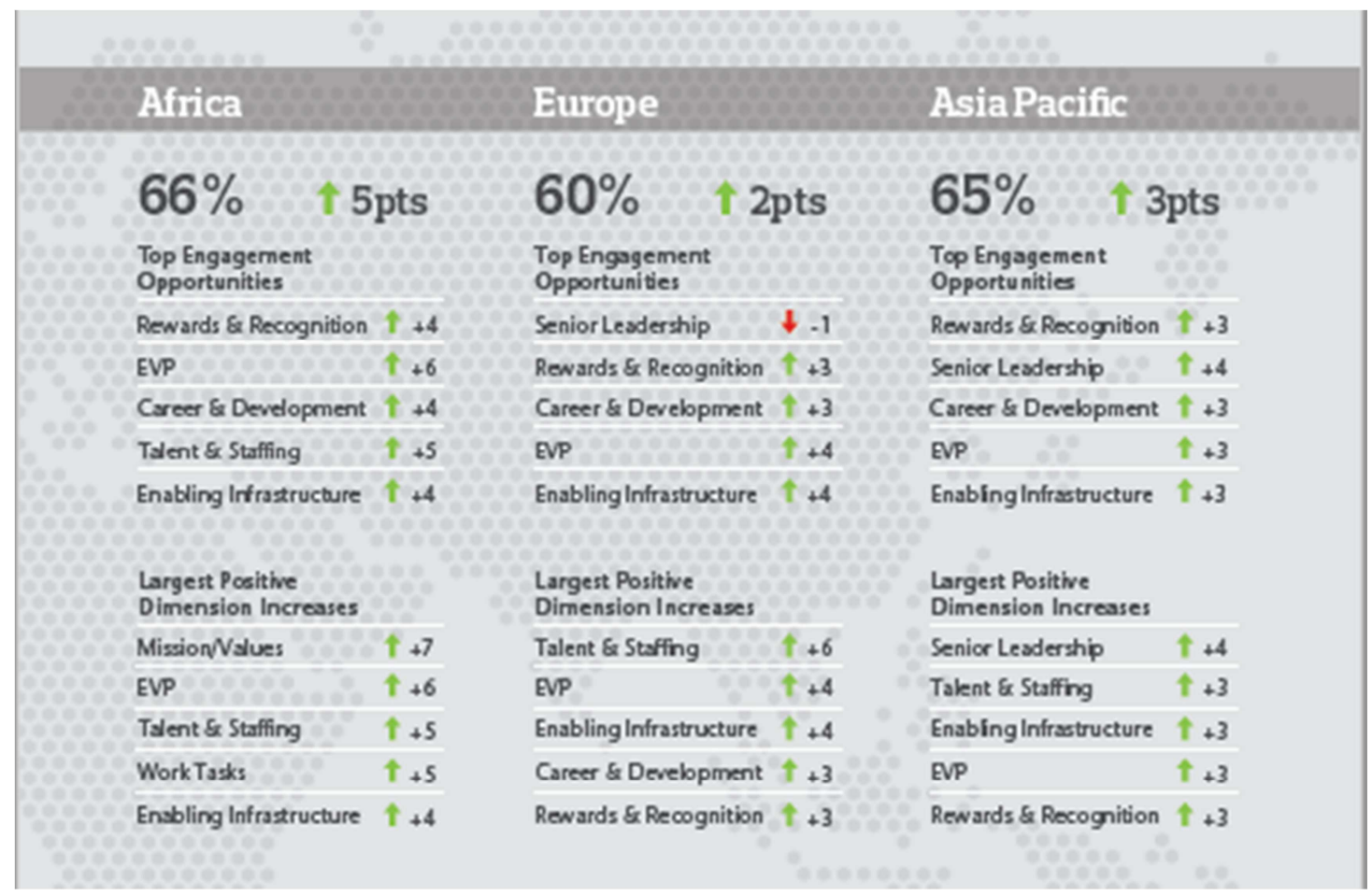

Figure 5. Results of Global Survey - Global Engagement Trends 2017, [18]. 
In the last year (2017) there has been economic stability in more mature regions and continued expansion in regions like Asia and Africa. Although most companies are continuing to face disruption and uncertainty, a robust, expanding economy means companies typically are investing more in people, and that makes the work experience much better for most employees. [18] (Ken Oehler, Aon's Global Culture \& Engagement Practice Leader)

\section{Recommendations}

It is recommended for $\mathrm{AON}$ to adopt the below strategic themes to help define, communicate and focus the strategy in such a way that it will not only help the organization to realise its financial goals but employees would be engaged and as well be retained within the company. The themes cut across all the strategic perspectives and included a series of linked objectives and initiatives that contribute to them, and the achievement of the high level goals;

Growth by maintaining existing baseline revenue turnover and extending to new market areas increasing cross-selling income, profitability and SPTI Margin performance. In the same way, being "SMART" in expenditures and investments, ensuring expenses are optimally managed through improved reporting and engagement of the business by finance to maintain a positive spread.

Retention by protecting and improving market share, particularly in high value sectors, improving the value to customer proposition through continuous improvement in access, convenience and expert diligent proactive service.

Delivering Colleague value by engaging in initiatives that will empower employees and promote better work relations

Service Delivery by improving effectiveness and efficiency of Aon's internal resources to deliver on the customer promise and aiming to always exceed expectations. Doing so, leveraging internal talent, technology and the significant information assets Aon has, to deliver an exceptional customer experience, remaining true to the Aon values and mission.

Compliance: There is increasing compliance demands from the regulator in the industry, which can be seen as barriers however also present growth opportunities for Aon as the leading broker in Botswana, particularly stemming from the new prudential rules. It is therefore imperative that Aon is seen to be fully conversant and compliant with the current and upcoming legislations, purposefully inculcating compliant behaviours throughout the organisation, and being an active contributor and advisor to the Government relating to matters of Governance in risk, brokering, employee benefits and retirement.

\section{Summary and Conclusion}

There is sufficient evidence and literature review that is focused on addressing issues of staff turnover and employee engagement and their implications on the overall performance of the organization. The evidence suggests that the study of employee engagement is on the rise; as such, organisations have to come on board to benefit from the recommendations and initiatives suggested by academics in relation to these important spectrums. Literature on staff turnover on the other hand is limited, that is, there is not much statistics published for the writer to conclude that the organisations are faced with a challenge of staff turnover. However, with the few cases of retrenchment, voluntary exits, retirement it is important for organisations to engage in staff retention strategies that will help cushion them back to reasonable performance should they experience the worst case scenarios of having many employees leaving the organization at the same time, more especially the high talented employees. It is therefore concluded that employee engagement has a positive relationship with organizational performance hence the organisations should maximize on promoting it. Staff turnover has a negative impact on the overall organizational performance therefore organisations should adopt measures of retaining employees. By investing and adopting such strategies business results or high performance will be achieved. The current study also establishes the need for future research to continue to explore the relationship between employee engagement and staff turnover and their implication on performance.

\section{References}

[1] LEAD, "AON BOTSWANA - FIVE YEAR STRATEGY (2018 - 2022)," AON, 2017.

[2] AON Hewitt, "Trends in Global Employee Engagement," 2011.

[3] Towers Perrin, "Working Today: Understanding What Drives Employee Engagement. The 2003 Towers Perrin Talent Report US Report," Towers Perrin, 2003.

[4] Towers Perrin, "Closing the Engagement Gap: A Road Map for Driving Superior Business Performance: Towers Perrin Global Workforce Study 2007-2008," Towers Perrin, Toronto, 2008.

[5] Towers Watson (firm), "2012 Global Workforce Study: Engagement at risk: driving strong performance in a volatile global environment," Towers Watson (firm), 2012.

[6] J. Smith and N. Macko, "Exploring The Relationship Between Employee Engagement And Employee Turnover," International Journal of Business Studies \& Research, vol. 6, no. 1, pp. 59-69, 2014.

[7] C. K. Sahoo and G. Sahu, "Effective Employee Engagement: The Mantra of Achieving Organizational Excellence," Management and Labour Studies, vol. 34, no. 1, p. 74, 2001.

[8] K. Ghuman, "A Prognostic Examination of Functional and Emotional Employee Engagement Drivers and their Impact on Employee Performance," FIIB Business Review, vol. 5, no. 2, p. 79, 2016.

[9] W. F. Cascio, "Strategies for responsible restructuring," Academy of Management Executive, vol. 16, no. 3, pp. 80-91, 2002. 
[10] R. J. Pech and B. W. Slade, "Employee disengagement: Is there evidence of a growing problem?," Handbook of Business Strategy, vol. 7, no. 1, pp. 21-25, 2006.

[11] N. Venkatramna and V. Ramanujam, "Measurement of Business Performance in Strategy Research: A Comparison of Approaches," The Academy of Management Review, vol. 11, no. 4, pp. 801-814, 1986.

[12] A. Johnson, H. Nguyen, M. Groth and L. White, "Workplace aggression and organisational effectiveness: The mediating role of employee engagement," Australian Journal of Management, vol. 43, no. 4, p. 618, 2018.

[13] A. M. Saks, "Antecedents and Consequences of Employee Engagement," Journal of Managerial Psychology, vol. 21, no. 7, pp. 600-619, 2006

[14] J. Anitha, "Determinants of employee engagement and their impact on employee performance," International Journal of Productivity and Performance Managemen, vol. 63, no. 3, pp. 308-323, 2014.

[15] W. H. Macey and B. Schneider, "The Meaning of Employee Engagement," Industrial and Organizational Psychology, vol. 1, no. 1, pp. 3-30, 2008.

[16] M. Bhebhe, "Strategic Management And Leadership Key To Organisational Perfomance: Findings From Zimbabwe," International Journal of Advanced Research and Publications, vol. 1 , no. 4 , p. $166,2017$.

[17] H. F. Vinje and M. B. Mittlemark, "Job engagement's paradoxical role in nurse burnout," Nursing and Health Sciences, vol. 9, 2007.

[18] AON, "2018 Trends in Global Employee Engagement: Global Employee Engagement Rebounds to Match Its All-Time High," 2018.

[19] U. A. Agarwal, S. Datta, S. Blake-Beard and S. Bhargava, "Linking LMX, innovative work behaviour and turnover intentions The mediating role of work engagement," The
Career Development International, vol. 17, no. 3, pp. 208-230, 2012.

[20] T. Rutledge, Getting Engaged: The New Workplace Loyalty, Toronto: Mattanie Press, 2006.

[21] L. L. S. N. Holbeche, In Search of Meaning in the Workplace, Forest Rd, Horsham: Roffey Park Institute Ltd, 2003.

[22] Gitanjali, Y. Sharma and B. Sharma, "Search for the Drivers of Employee Engagement among Executives of a Manufacturing Organisation," Management and Labour Studies, p. 190, 2010.

[23] S. Kular, M. Gatenby, C. Rees and E. Soan, "Employee Engagement: A Literature Review," Kingston University, 2008.

[24] S. M. Kompaso and S. M. Sridevi, "Employee Engagement: The Key to Improving Performance," International Journal of Business and Management, vol. 5, no. 12, p. 89, 2010.

[25] K. Alfes, A. D. Shantz, C. Truss and E. C. Soane, "The link between perceived human resource management practices, engagement and employee behaviour: a moderated mediation model," The International Journal of Human Resource Management, vol. 24, no. 2, pp. 330-351, 2013.

[26] Managing Director AON, "Staff Address Meeting," in AON Botswana Corporate Strategy 2018-2022, Gaborone, 2018.

[27] E.-K. Choi, J. Zhao, H. Joung and E. Suh, "Conceptual Framework for the Relationships among Job-Training Satisfaction, Job Satisfaction, and Turnover Intention in Foodservice Operations," Journal of Culinary Research, vol. 20, no. 5, p. 12, 2014.

[28] B. B. A. Otieno, E. W. Waiganjo and A. Njeru, "Effect of Employee Engagement on Organisation Performance in Kenya's Horticultural Sector," International Journal of Business Administration, vol. 6, no. 2, pp. 77-85, 2015.

[29] L. Edgren and K. Barnard, "Complex adaptive systems for management of integrated care," Leadership in Health Services, vol. 25, no. 1, pp. 39-51, 2012. 